\title{
Refractive , Topographic and Tomographic analysis of Keratoconus in Egypt
}

\author{
Esraa A. AbdElkader, Abdelmonem M. Hamed, Ahmed A. Tabl
}

\begin{abstract}
Department of ophthalmology, Benha faculty of medicine, Banha University, Egypt.

Correspondence to: Esraa A. AbdElkader, Department of ophthalmology, Benha faculty of medicine, Banha University, Egypt.
\end{abstract}

Email:

dres201426@gmail.com

Received: 20 July 2021

Accepted: 4 December 2021

\begin{abstract}
:
Objectives: The aim of this study was to evaluate the demographic profile, refractive, topographic and tomograghic characters of keratoconus patients in Egypt. Patients and Methods: This study was designed as a retrospective cohort clinical study. The study met the ethical criteria of the Institutional Review Board (IRB) in Faculty of Medicine Benha University with approval No. of (MS 32-12-2019). Our study included 102 eyes of 51 patient in the keratoconus group and 100 eyes of 50 patients in the control group. The study was designed as a retrospective cohort clinical study on keratoconus patients who attended at $\mathrm{Al}$ Ferdaws eye hospital in the period from January 2016 to December 2020. Study groups: Group 1: normal eyes as a control group. Group 2: keratoconus group (KC). Data Synthesis: The results analyzed using SPSS25, T-test, MannWhitney $U$ test and Chi-square test. Findings: There was
\end{abstract} clinically significant difference between normal and $\mathrm{KC}$ cases regarding the cylinder, BCVA, keratometric power of anterior and posterior surface on both flat and steep meridian.also K max and $\mathrm{km}$.,Q value at $6 \mathrm{~mm}$., thinnest location, relative thickness map average,thickness profile map average (PPI),highest elevation front and back,corneal irregularity indices, corneal aberrometric values, BAD_ D and ARTmax. Conclusion: We found no significant association between the severity of $\mathrm{KC}$ with age and sex. many parameters in topography and tomography were efficient in differentiating normal cases from keratoconus cases even in early disease.

Key words: keratoconus, cornea, topography, pentacam 


\section{Introduction}

Keratoconus $(\mathrm{KC})$ is a bilateral asymmetrical and progressive corneal ectasia that leads to visual impairment via causing irregular astigmatism, myopia, higher order aberrations (HOAS), and corneal scar. ${ }^{[1]}$ It typically presents in adolescence and progress until the third or fourth decade of life. ${ }^{[2]}$

The prevalence of $\mathrm{KC}$ in Asian populations is about 4 times higher than other ethnic populations, with the highest prevalence reported in the Mediterranean region and Middle East. ${ }^{[3-5]}$

The prevalence of $\mathrm{KC}$ varies in different countries, indicating the possible role of genetics in its etiology. ${ }^{[6]}$

It may be an isolated condition or occur with other ocular and systemic disorders such as atopy, vernal disease, Down syndrome, retinitis pigmentosa, Turner syndrome, connective tissue disorders such as Marfan syndrome, Ehlers-Danlos syndrome, osteogenesis imperfecta, and pseudoxanthoma elasticum. $\mathrm{KC}$ has a strong association with eye rubbing,repeated trauma from contact lenses, and allergic eye disease. $^{[7]}$

$\mathrm{KC}$ should be suspected in any patient with significant irregular astigmatism, especially if unstable and increasing over time. In the early stages of the disease, there is altered metabolic activity that may lead to biomechanical instability and stretching of the corneal tissues. ${ }^{[8]}$

There is accompanying tissue loss with disease progression. In addition, there is a loss of correlation between the anterior and posterior corneal curvature. ${ }^{[9]}$ Progressive corneal thinning and distortion causes a conical or cone-shaped protrusion, which may be visible at the slit lamp in advanced cases. ${ }^{[10]}$ In early disease, the condition may go undiagnosed unless assessments of the posterior and anterior corneal surfaces are undertaken using corneal tomography. ${ }^{[11]}$

In the past, keratoconus was diagnosed using Placido-disc based topographers that analyze rings that are reflected off the corneal surface, which are only able to evaluate the anterior surface of the cornea. Unlike corneal topographers, tomographers generate a three-dimensional map of the anterior segment and provide information about the corneal thickness. Schiempflug imaging is one of the most commonly used techniques for corneal tomography. The development of the Scheimpflug camera system (Pentacam, Oculus Optikgerate 
gmbh, Wetzlar, Germany) also enabled evaluation of the posterior corneal surface by generating cross-sectional images by a rotating camera. This device allowed the detection of early changes originating in the posterior cornea in clinically normal patients, which was a major breakthrough in the diagnosis and monitoring of the disease. $^{[12-15]}$

The Global Consensus on Keratoconus and Ectatic Disease (2015), recommended the following criteria for diagnosis of keratoconus: abnormal posterior elevation, abnormal corneal thickness distribution and corneal thinning ${ }^{[10]}$

There are Several classification systems for keratoconus have been proposed in the literature; The Amsler-Krumeich keratoconus classification is the oldest and most commonly used classification system for keratoconus. It relies on anterior surface topography. This system grades keratoconus into 4 stages based on spectacle refraction, central keratometry, presence or absence of scarring, and central corneal thickness. ${ }^{[16]}$

Other studies such as the Collaborative Longitudinal Evaluation of Keratoconus (CLEK) Study used changes in vision, keratometry, biomicroscopic signs, corneal scarring, and vision-specific quality of life, as measures to define stage and severity of disease. $^{[17]}$

A new classification ABCD keratoconus grading system was introduced in 2016 utilizing current tomographic data and it is dependent on corneal tomography. It includes the anterior (A) and posterior (B) average radii of curvature, thinnest pachymetric values (C) and best distance visual acuity (D) as well as the degree of scarring. The system classifies keratoconus into 5 stages from 0 to 4 . $^{[18]}$

\section{Materials and methods}

Search Strategy: The study was designed as a retrospective cohort clinical study on keratoconus patients who attended at $\mathrm{Al}$ Ferdaws eye hospital in the period from January 2016 to December 2020.

\section{Study groups}

1- Group 1: normal eyes as a control group

2- Group 2: keratoconus group (KC)

We further subdivided the $\mathrm{KC}$ group according to Amsler-Krumeich classification to $\mathrm{KC} 1, \mathrm{KC} 2, \mathrm{KC} 3, \mathrm{KC} 4$ and forme fruste (FF) and subdivided the normal group to 3 subgroups according to the astigmatism to: with the rule(WTR), against the rule(ATR) and oblique. 
Ethical approval: The study met the ethical criteria of the Institutional Review Board (IRB) in Faculty of Medicine Benha University. (MS 32-12-2019)

\section{Study Selection:}

The patients were included if they fulfilled the following criteria:

Inclusion Criteria: Male or female patients included. Patients' age: All patients must be above 20 years old. In group 2, patients with Keratoconus based on Amsler-Krumeich classification using Pentacam HR tomographer (OCULUS Optikgeräte $\mathrm{GmbH}$, Germany). All eyes had clear unoperated corneas, and were not using contact lenses.

Patients with the following criteria were excluded from our study:

Exclusion Criteria: For group 1: Severe dry eye, corneal scar, severe allergic conjunctivitis, a history of eye surgery, glaucoma, cataract, a history of herpes simplex keratitis, pregnancy, breast-feeding, thyrotoxicosis, hypothyroidism, and use of certain medications, such as Accutane (Isotretinoin, Accutane ${ }^{\mathrm{TM}}$ Roche ${ }^{\circledR}$, Canada). For group 2: previous corneal trauma, previous corneal surgery, less than 20 years old, patients wearing contact lens at time of presentation.

\section{Sample Size}

Our sample size was 101 patient; includes 102 eyes of 51 patient in the keratoconus group and 100 eyes of 50 patient in the control group.

\section{Data Extraction:}

A complete ophthalmologic examination, including manifest and subjective refraction, uncorrected distance visual acuity (UDVA) and corrected distance visual acuity (BCVA), slit lamp biomicroscopy, applanation tonometry, indirect ophthalmoscopy, and In addition, topographic, tomographic, topometric, and aberrometric maps were examined using Pentacam HR tomographer (OCULUS Optikgeräte GmbH, Germany) were performed on all eyes. The device is a noninvasive anterior segment tomographer that uses a 475-nm monochromatic slit of light to illuminate the cornea and a 1.45megapixel camera for photography. The camera rotates about the line of fixation during the scanning period. There are several scanning options available including a 25-picture (1 second) scan, a 50-picture (two second) scan, and a cornea fine (50 pictures in 1 second) scan. Using data from these pictures, the system calculates a 3D model of the anterior segment from up to 
138,000 true elevation points. Any eye movement is detected by a second camera and corrected for in the process. ${ }^{[19]}$

\section{Data Synthesis:}

○ The results analyzed using SPSS25. Normally distributed continuous data expressed as mean \pm standard deviation and not-normally distributed continuous data expressed as median (range).

- Categorical data expressed as percentage. T-test used to compare between two groups in case of normally distributed variables.

○ Not-normally distributed variables analyzed using Mann-Whitney $\mathrm{U}$ test. Chi-square test used to compare between the qualitative.

- Other kinds of tests performed when necessary.

Results considered statistically significant at a p-value of less than 0.05 .

\section{Results}

In the keratoconus group 17 patients were males and 34 patients were females with a mean age of $29.25 \pm 8.13$ years. In the control group 23 patients were males and 27 patients were females with a mean age of $30.24 \pm 9.28$ years. We found no significant difference between both groups regarding age or gender.(Table 1).
We found that the difference between control group and $\mathrm{KC}$ group was significant regarding BCVA and cylinder before and after cyclodilatation ( $\mathrm{p}$ value $<0.001$ ) and not significant regarding sphere either before ( $\mathrm{p}$ value $=0.988$ ) or after cyclodilatation ( $\mathrm{p}$ value $=0.912)($ Table 1$)$.

The difference between $\mathrm{KC}$ group and control group was significant in the following parameters; True Net Power k1,k2, p-max ( $\mathrm{p}$ value $<0.001$ ) and astigmatism ( $\mathrm{p}$ value $=0.001)$. Anterior $\mathrm{k} 1(\mathrm{p}$ value $=0.001), \mathrm{k} 2, \mathrm{k}$ mean, $\mathrm{k}$ Max front, topographic astigmatism ( $\mathrm{p}$ value $<0.001$ ). Posterior $\mathrm{k} 1, \mathrm{k} 2$ ( $\mathrm{p}$ value $<0.001$ ), post $\mathrm{k}$ mean ( $\mathrm{p}$ value $=0.001$ ), SRAX, IS,SI and $\mathrm{Q}$ value (p value $<0.001$ ). (Table 1).

Regarding pachymetry ; The difference between $\mathrm{KC}$ and control group was significant regarding thinnest location TL, vertical displacement of TL(Y) (p value <0.001), difference between apex and TL $(p$ value $=0.001$ ), pachymetry pattern ( $\mathrm{p}$ value $=$ 0.002). relative thickness map average ( $p$ value $<0.001$ ), thickness profile map average ( $\mathrm{p}$ value $<0.001$ ) and shape ( $\mathrm{p}$ value $=0.001$ ). The difference wasn't significant between KC and control group regarding pachy apex $(p$ value $=0.977$ ), horizontal displacement of the $\mathrm{TL}(\mathrm{X})(\mathrm{p}$ value $=0.64)$ and difference 
between superior and inferior pachymetry at 5 $\mathrm{mm}$ zone $(\mathrm{p}$ value $=0.522)$. Table 2$)$

Regarding elevation maps; the difference between $\mathrm{KC}$ group and control group was significant in the following parameters; highest elevation front at central $5 \mathrm{~mm}$ (toric ellipsoid), highest elevation back at central 5 $\mathrm{mm}$ (toric ellipsoid), highest elevation front at TL(BFS), highest elevation back at TL (BFS) (p value $<0.001$ ) and shape of elevation back map ( $\mathrm{p}$ value $=0.001) \quad($ Table 4),(fig.1) .Regarding shape of elevation back in $\mathrm{KC}$ group we found that $43.1 \%$ tongue followed by $39.2 \%$ isthmus and least was nipple $17.6 \%$. While in control group we found most cases have non specific shape or near to isthmus shape $64.8 \%$, tongue $14.8 \%$ and least nipple $1.9 \%$ of cases.

The difference between the $\mathrm{KC}$ group and control group was statistically significant regarding total RMS, RMS(HOA), corneal coma at 90 and 0 at 3rd order aberration, 90 and 0 at 5 th order aberration, BAD D, and ARTI max (p value <0.001).(Table 2),(fig.2, 3).

Regarding inter eye asymmetry score ; most cases in $\mathrm{KC}$ group had score 5 (33.3\%) followed by score $4(23.5 \%)$ then score 2 $(17.6 \%)$, score $3(13.7 \%)$ and least for score 1 $(11.8 \%)$. While in control group most cases had score $0(40 \%)$ followed by score $1(34 \%)$, score $2(16 \%)$ and finally score 3 (10\%).(fig.4).

In comparing $\mathrm{KC}$ groups there was no significant difference between the $\mathrm{KC}$ groups regarding age or gender. (Table 3), BCVA decreased significantly with increased severity while refraction increased significantly with increased severity(Table 3),thinnest location and pachy apex decrease with increased severity of the disease (Table 4), regarding highest elevation front and back using either modes; BFS or toric ellipsoid we found that the values increased significantly with increasing severity of the disease(Table 4). There was statistically significant difference regardind SRAX. On pairwise comparison, the difference was significant between FF groups and $\mathrm{KC} 3$ groups. Q value was normal in $100 \%$ of FF cases, $80 \%$ of $\mathrm{KC} 1$ and $37.5 \%$ of KC2 , RMS (HOA) was abnormal in $100 \%$ of all groups. ART-max was abnormal in (78.9\%) of $\mathrm{FF}$ cases, $(73.3 \%)$ of $\mathrm{KC1}$ and $100 \%$ abnormal in $\mathrm{KC} 2, \mathrm{KC} 3$ and $\mathrm{KC} 4$ so it could be normal in few cases of early $\mathrm{KC}$ disease. BAD-D was pathological in $100 \%$ of cases in $\mathrm{KC} 2, \mathrm{KC} 3$ and $\mathrm{KC} 4 ., 80 \%$ in $\mathrm{KC} 1$ and $47.4 \%$ of FF cases, Suspecious in $47.4 \%$ of FF cases and $13.3 \%$ of $\mathrm{KC} 1$ cases.(Table 4).

In comparing normal groups There was statistically significant difference between the 
studied groups regarding age On LSD comparison, the difference was significant between ATR and oblique astigmatism group.(Table 5). There was statistically non significant difference between the studied groups regarding BCVA, spherical, cylindrical refraction, thinnest local, relative thickness map and pachymap pattern. Q value, ART- $\max$ and BAD-D were normal in $100 \%$ of cases but RMS (HOA) was normal in (58.8\%) of WTR cases, (72.1\%) of ATR cases and $(80 \%)$ of oblique astigmatism cases so RMS(HOA) shouldn't be used alone in assessing normal cases.(Table 5).

Table (1): Comparison between the studied groups regarding demographic data, visual acuity , refraction and

\begin{tabular}{|c|c|c|c|c|}
\hline \multirow[t]{2}{*}{$\begin{array}{l}\text { curvature parameters. } \\
\text { Parameter }\end{array}$} & \multicolumn{2}{|c|}{ Groups } & \multicolumn{2}{|c|}{ Test } \\
\hline & $\begin{array}{c}\text { Keratoconus group } \\
\mathrm{N}=\mathbf{5 1}(\%)\end{array}$ & $\begin{array}{c}\text { Control group } \\
\mathrm{N}=\mathbf{5 0}(\%)\end{array}$ & $\chi^{2} / \mathrm{t}$ & $\mathrm{P}$ \\
\hline \multicolumn{5}{|l|}{ Gender: } \\
\hline Male & $17(33.3)$ & $23(46)$ & \multirow{2}{*}{0.1} & \multirow{2}{*}{0.752} \\
\hline Female & $34(66.7)$ & $27(54)$ & & \\
\hline \multicolumn{5}{|l|}{ Age (year): } \\
\hline \multirow[t]{2}{*}{ Mean \pm SD } & $29.25 \pm 8.13$ & $30.24 \pm 9.28$ & -0.568 & \multirow[t]{2}{*}{0.571} \\
\hline & Median(range) & Median(range) & $\mathrm{Z}$ test & \\
\hline \multicolumn{5}{|l|}{ BCVA } \\
\hline Median(range) & $0.55(0.05-1)$ & $1(0.1-1)$ & -5.097 & $<0.001 * *$ \\
\hline Sphere & $-2.5(-16,4.5)$ & $-3.34(-13,3.25)$ & -0.15 & 0.988 \\
\hline Cylinder & $-3.25(-11,0)$ & $-1.25(-4.75,-0.25)$ & -6.938 & $<0.001 * *$ \\
\hline Axis & $125(0,180)$ & $120(5-180)$ & -2.418 & $0.016^{*}$ \\
\hline Cyclosphere & $-1.625(-16,5)$ & $-2.25(-8.75,1.25)$ & -0.11 & 0.912 \\
\hline Cyclocylinder & $-3.375(-8.75,0)$ & $-1.25(-3.75,-0.5)$ & -4.444 & $<0.001 * *$ \\
\hline \multirow{2}{*}{ Cyclocylinder axis } & $87.5(0-180)$ & $95(5-180)$ & -1.089 & 0.276 \\
\hline & Mean \pm SD & Mean \pm SD & & \\
\hline Anterior K1 & $46.13 \pm 4.47$ & $42.2 \pm 1.56$ & 8.384 & $0.001 * *$ \\
\hline Anterior $\mathrm{K} 1$ axis & $90.1(1.2,179)^{¥}$ & $93.5(0.8,179.4)^{¥}$ & -0.577 & 0.577 \\
\hline Anterior K2 & $49.28 \pm 5.39$ & $43.49 \pm 1.39$ & 10.398 & $<0.001 * *$ \\
\hline Anterior K2 axis & $90.1(3.8,176.4)^{¥}$ & $88.9(0.4,169.1)^{¥}$ & -0.179 & 0.858 \\
\hline Anterior Km & $51.44 \pm 7.87$ & $42.81 \pm 1.51$ & 9.721 & $<0.001 * *$ \\
\hline KMax front & $53.84 \pm 8.6$ & $43.96 \pm 1.48$ & 11.438 & $<0.001 * *$ \\
\hline K Max- K2 & $3.45(0.2-16)^{¥}$ & $0.4(0.1-2.4)^{¥}$ & -11.428 & $<0.001 * *$ \\
\hline Topographic Astigmatism & $-2.95(-9.6,2.2)^{¥}$ & $-1.1(-4.1,-0.1)^{¥}$ & -7.445 & $<0.001^{* *}$ \\
\hline $\begin{array}{l}\text { DD power of T. astig. VS } \\
\text { manifest astig. }\end{array}$ & $0.1(-8.5,6.25)^{¥}$ & $0.05(-1.1,1.5)^{¥}$ & -0.207 & 0.836 \\
\hline DD axis of T. astig. VS & $4.3(-174.9,171.6)^{¥}$ & $2.85(-177.8,172.4)^{¥}$ & -0.89 & 0.374 \\
\hline I-S & $4.31(0.03,20.66)^{¥}$ & $0.41(0,1.4)^{¥}$ & -9.121 & $<0.001 * *$ \\
\hline S-I & $1.8(0.3,3.8)$ & $0.4(-0.33,3.5)$ & -4.211 & $<0.001 * *$ \\
\hline SRAX & $12.12 \pm 19.45^{¥}$ & $8.02 \pm 7.3^{¥}$ & -11.007 & $<0.001 * *$ \\
\hline$Q$ value & $-0.72(-2.81,0.3)$ & $-0.25(-0.5,0.03)$ & -11.007 & $<0.001 * *$ \\
\hline
\end{tabular}

$\mathrm{Z}$ Mann Whitney test $\mathrm{t}$ Independent sample $\mathrm{t}$ test, $\chi^{2}$ Chi square test $\mathrm{t}$ Independent sample $\mathrm{t}$ test, $* \mathrm{p}<0.05$ is statistically significant ${ }^{* *} \mathrm{p} \leq 0.001$ is statistically highly significant, ${ }^{¥}$ data is represented as median (Range) 
Table (2): Comparison between the studied groups regarding pachymetry, elevation and some topographic parameters.

\begin{tabular}{|c|c|c|c|c|}
\hline \multirow{2}{*}{ Parameter } & \multicolumn{2}{|c|}{ Groups } & \multicolumn{2}{|c|}{ Test } \\
\hline & $\begin{array}{c}\text { Keratoconus group } \\
\text { Median (range) }\end{array}$ & $\begin{array}{l}\text { Control group } \\
\text { Median (range) }\end{array}$ & $\chi^{2} / \mathrm{t}$ & $\mathbf{P}$ \\
\hline Thinnest location & $464.23 \pm 48.28^{¥}$ & $551.9 \pm 28.08^{¥}$ & -15.737 & $<0.001^{* *}$ \\
\hline Thinnest local X & $-0.13(-1.39,1.58)$ & $-0.04(-1.21,0.97)$ & -0.467 & 0.64 \\
\hline Thinnest local Y & $-0.44(-1.34,0.68)$ & $-0.28(-0.89,0.14)$ & -3.266 & $<0.001 * *$ \\
\hline Pachy apex & $473.9 \pm 47.97^{¥}$ & $556.08 \pm 27.73^{¥}$ & -0.117 & 0.977 \\
\hline Difference ()Apex \& TL & $8(0-39)$ & $4(0-11)$ & -6.479 & $0.001 * *$ \\
\hline Pachymap pattern & & & & \\
\hline CONC & $11(10.8)$ & $14(14)$ & & \\
\hline Dome & $43(42.2)$ & $19(19)$ & 12.771 & $0.002 *$ \\
\hline Horizontal & $48(47.1)$ & $67(67)$ & & \\
\hline IS DD pachy & $29(-30,93)$ & $27.5(-10,94)$ & -0.641 & 0.522 \\
\hline $\begin{array}{l}\text { Highest elevation front } \\
\text { central } 5 \mathrm{~mm} \text { (toric ellipsoid) }\end{array}$ & $7(1,48)$ & $2(0,5)$ & -10.461 & $<0.001 * *$ \\
\hline $\begin{array}{l}\text { Highest elevation back central } \\
\text { 5mm(toric ellipsoid) }\end{array}$ & $15(5,88)$ & $6(3,14)$ & -10.419 & $<0.001 * *$ \\
\hline $\begin{array}{l}\text { Highest elevation front } \\
\text { TL(BFS) }\end{array}$ & $17.5(3,73)$ & $3(-2,8)$ & -11.876 & $<0.001 * *$ \\
\hline $\begin{array}{l}\text { Highest elevation back } \\
\text { TL(BFS) }\end{array}$ & $44.5(3,135)$ & $5(-1,14)$ & -11.648 & $<0.001 * *$ \\
\hline $\begin{array}{l}\text { shape of elevation back map: } \\
\text { Isthmus } \\
\text { Nipple } \\
\text { Tongue }\end{array}$ & $\begin{array}{l}40(39.2) \\
18(17.6) \\
44(43.1)\end{array}$ & $\begin{array}{l}35(64.8) \\
1(1.9) \\
8(14.8)\end{array}$ & 20.691 & $0.001 * *$ \\
\hline $\begin{array}{l}\text { Relative thickness map } \\
\text { average }\end{array}$ & $-9.75(-53,-1.1)$ & $-3.1(-5.8,3.7)$ & -10.845 & $<0.001 * *$ \\
\hline $\begin{array}{l}\text { Thickness profIle map } \\
\text { average }\end{array}$ & $1.895(0.69,4.89)$ & $0.91(0.7,1.18)$ & -11.125 & $<0.001 * *$ \\
\hline $\begin{array}{l}\text { Thickness profile map shape: } \\
\text { N } \\
\text { QS } \\
\text { S shape }\end{array}$ & $\begin{array}{l}41(40.2) \\
44(43.1) \\
16(15.7)\end{array}$ & $\begin{array}{c}100(100) \\
0(0) \\
0(0)\end{array}$ & 85.677 & $0.001 * *$ \\
\hline & & & $\mathrm{Z} / \mathrm{t}$ & $\mathbf{P}$ \\
\hline Total RMS & $6.42(0.86,32.28)$ & $1.47(0.42,4.96)$ & -11.241 & $<0.001 * *$ \\
\hline RMS(HOA) & $1.61(0.32,7.33)$ & $0.35(0.21-1.08)$ & -11.395 & $<0.001 * *$ \\
\hline Cornea coma at $903^{\text {rd }}$ order & $1.04(0.02,6.76)$ & $0.11(0-0.75)$ & -11.302 & $<0.001 * *$ \\
\hline Corneal coma $03^{\text {rd }}$ order & $0.45(0,2.74)$ & $0.089(0.01,0.36)$ & -9.916 & $<0.001 * *$ \\
\hline Corneal coma $905^{\text {th }}$ order & $0.14(0,1.17)$ & $0.02(0,0.12)$ & -8.706 & $<0.001 * *$ \\
\hline Corneal coma $05^{\text {th }}$ order & $0.07(0,1.07)$ & $0.018(0,0.1)$ & -7.34 & $<0.001 * *$ \\
\hline BAD- D & $6.98(0.1,25.65)$ & $0.63(-0.61,1.55)$ & -11.934 & $<0.001 * *$ \\
\hline ARTI- Max & $186.5(51,691)$ & $473.5(340,664)$ & -11.452 & $<0.001 * *$ \\
\hline
\end{tabular}

${ }^{¥}$ data is represented as mean $\pm \mathrm{SD} * * \mathrm{p} \leq 0.001$ is statistically highly significant. 
Table (3): Comparison between groups of patients with keratoconus regarding demographic data,vision and refraction.

\begin{tabular}{|c|c|c|c|c|c|c|}
\hline & $\begin{array}{l}\text { FF group } \\
\text { Mean } \pm \text { SD }\end{array}$ & $\begin{array}{c}\text { KC1 group } \\
\text { Mean } \pm \text { SD }\end{array}$ & $\begin{array}{c}\text { Group } \\
\text { KC2 group } \\
\text { Mean } \pm \text { SD }\end{array}$ & $\begin{array}{c}\text { KC3 group } \\
\text { Mean } \pm \text { SD }\end{array}$ & $\begin{array}{c}\text { KC4 group } \\
\text { Mean } \pm \text { SD }\end{array}$ & $\mathbf{P}$ \\
\hline Age & $30.64 \pm 7.42$ & $27.71 \pm 6.43$ & $32.07 \pm 8.72$ & $24.33 \pm 7.06$ & $28 \pm 11.98$ & 0.299 \\
\hline $\begin{array}{l}\text { Gender: } \\
\text { Male }\end{array}$ & $7(63.63)$ & $2(14.3)$ & $4(26.7)$ & $4(66.7)$ & $0(0)$ & 0.199 \\
\hline Female & $\begin{array}{c}4(36.4) \\
\text { Median(range) }\end{array}$ & $\begin{array}{c}12(85.71) \\
\text { Median(range) }\end{array}$ & $\begin{array}{c}11(73.3) \\
\text { Median(range }\end{array}$ & $\begin{array}{c}2(33.3) \\
\text { Median(range) }\end{array}$ & $\begin{array}{c}5(100) \\
\text { Median(range) }\end{array}$ & \\
\hline BCVA & $0.9(0.3-1)$ & $0.7(0.3-1)$ & $0.5(0.1-0.8)$ & $0.4(0.05-0.7)$ & $0.4(0.3-0.5)$ & $<0.001 * *$ \\
\hline Sphere & $-1.5(-16,4.5)$ & $-1.63(-13,4.5)$ & $-2.75(-15,2)$ & $-5(-11,0)$ & $-9.75(-13,-5.25)$ & $<0.001 * *$ \\
\hline Cylinder & $-2(-7.25,0)$ & $-2.38(-7.5,0)$ & $-3.75(-8.75,-0.25)$ & $-4.5(-8.75,-2)$ & $-5.5(-11,-0.75)$ & $0.002 *$ \\
\hline
\end{tabular}

$* \mathrm{p}<0.05$ is statistically significant $* * \mathrm{p} \leq 0.001$ is statistically highly significant

Table (4): Comparison between keratoconus groups regarding pachymetry, elevation and other topographic parameters

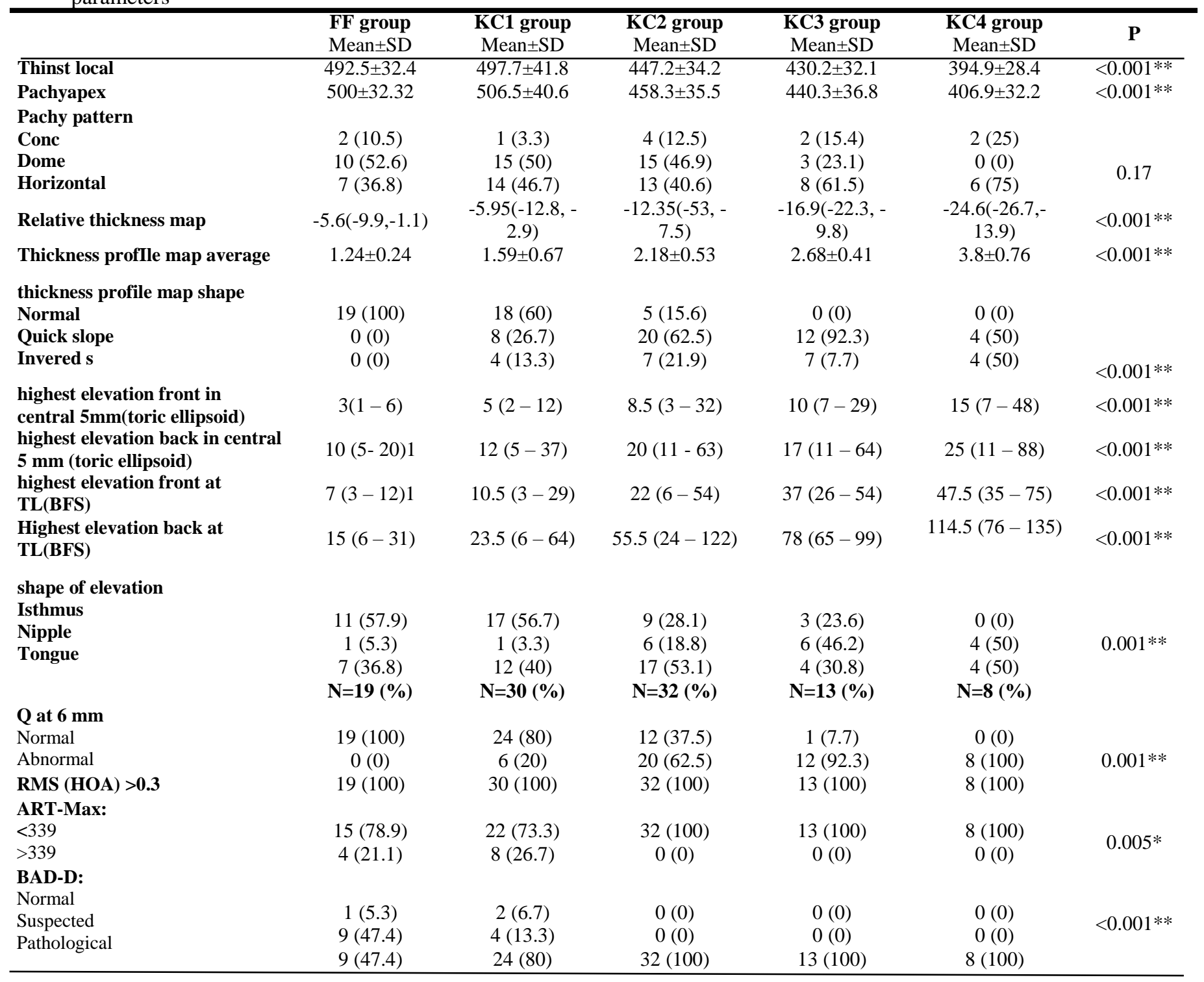


Benha medical journal vol. 39, special issue (ophthalmology), 2022

Table (5): Comparison between normal groups regarding demographic data and some topographic indices

\begin{tabular}{|c|c|c|c|c|}
\hline & $\begin{array}{l}\text { WTR group } \\
\text { Mean } \pm \text { SD }\end{array}$ & $\begin{array}{c}\text { ATR group } \\
\text { Mean } \pm \text { SD }\end{array}$ & $\begin{array}{c}\text { Oblique astigmatism group } \\
\text { Mean } \pm \text { SD }\end{array}$ & $\mathbf{P}$ \\
\hline Age & $32.86 \pm 9.62$ & $27.52 \pm 7.31$ & $39.25 \pm 8.72$ & $0.005^{*}$ \\
\hline \multicolumn{5}{|l|}{ Gender: } \\
\hline Male & $5(55.6)$ & $13(41.9)$ & $9(90)$ & \multirow{3}{*}{0.115} \\
\hline \multirow[t]{2}{*}{ Female } & $4(44.4)$ & $18(58.1)$ & $1(10)$ & \\
\hline & $\mathrm{N}=17(\%)$ & $\mathrm{N}=68(\%)$ & $\mathrm{N}=15(\%)$ & \\
\hline \multicolumn{5}{|l|}{$Q$ at $6 \mathrm{~mm}$} \\
\hline Normal & $17(100)$ & $68(100)$ & $15(100)$ & \\
\hline \multicolumn{5}{|l|}{ RMS (HOA) } \\
\hline$>0.3$ & $10(58.8)$ & $49(72.1)$ & $12(80)$ & \multirow{2}{*}{0.421} \\
\hline$<0.3$ & $7(41.2)$ & $19(27.9)$ & $3(20)$ & \\
\hline \multicolumn{5}{|l|}{ ART-Max: } \\
\hline$>339$ & $17(100)$ & $68(100)$ & $15(100)$ & \\
\hline \multicolumn{5}{|l|}{ BAD-D: } \\
\hline Normal & $17(100)$ & $68(100)$ & $15(100)$ & \\
\hline
\end{tabular}

${ }^{*} \mathrm{p}<0.05$ is statistically significant $* * \mathrm{p} \leq 0.001$ is statistically highly significant

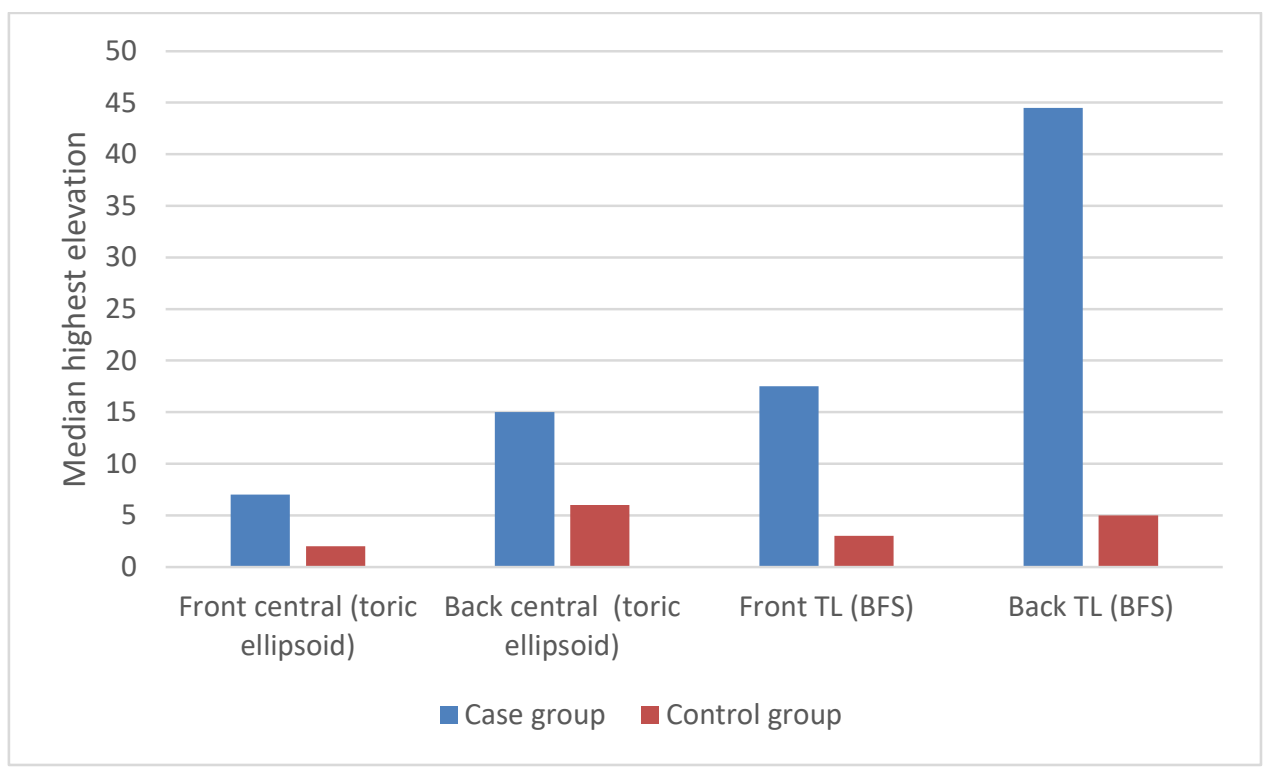

Figure (1): Multiple bar chart showing highest elevation values among the studied groups. 


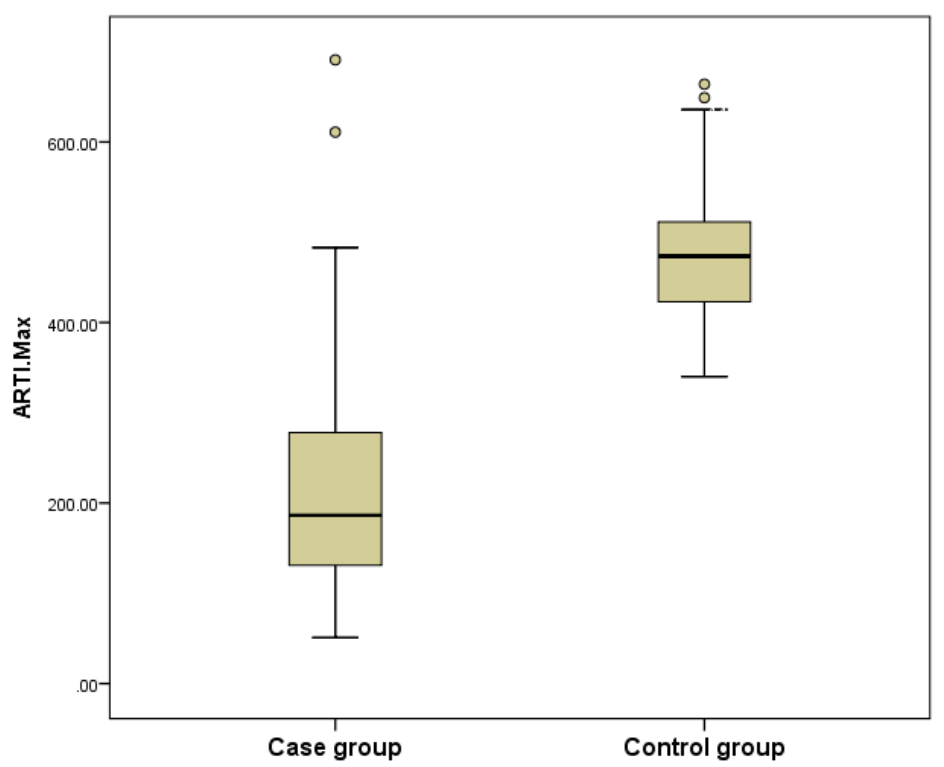

Figure (2): Boxplot chart showing ARTI Max values among the studied groups.

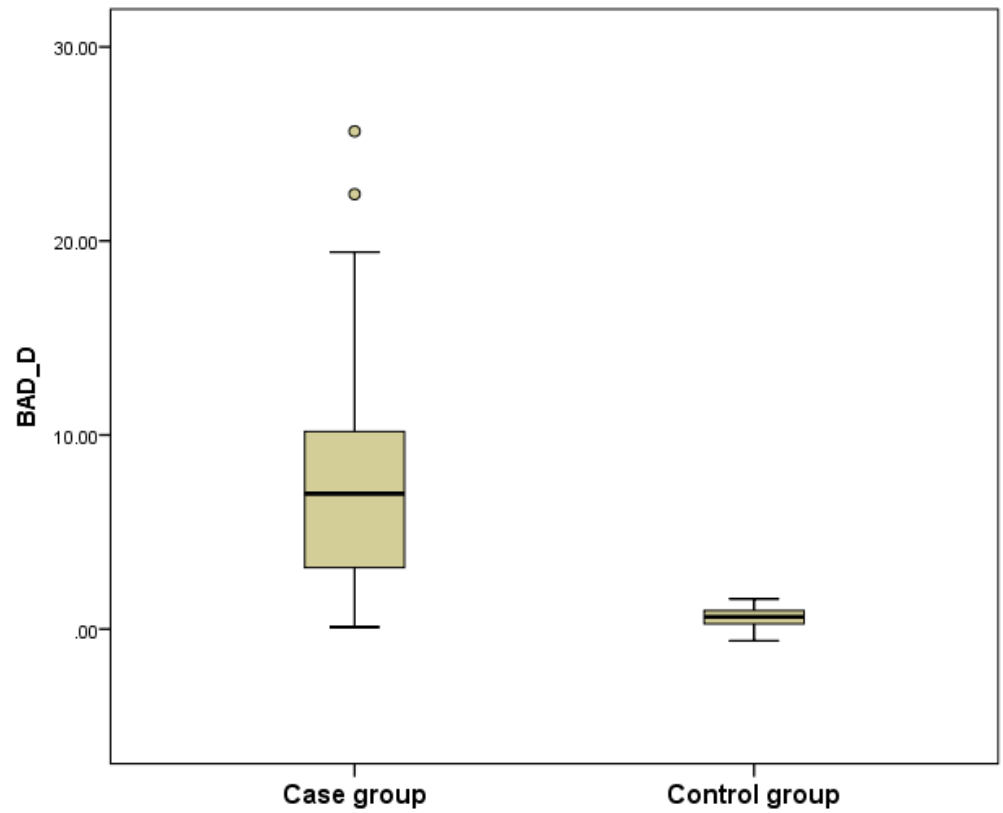

Figure (3): Multiple bar chart showing BAD-D values among the studied groups 


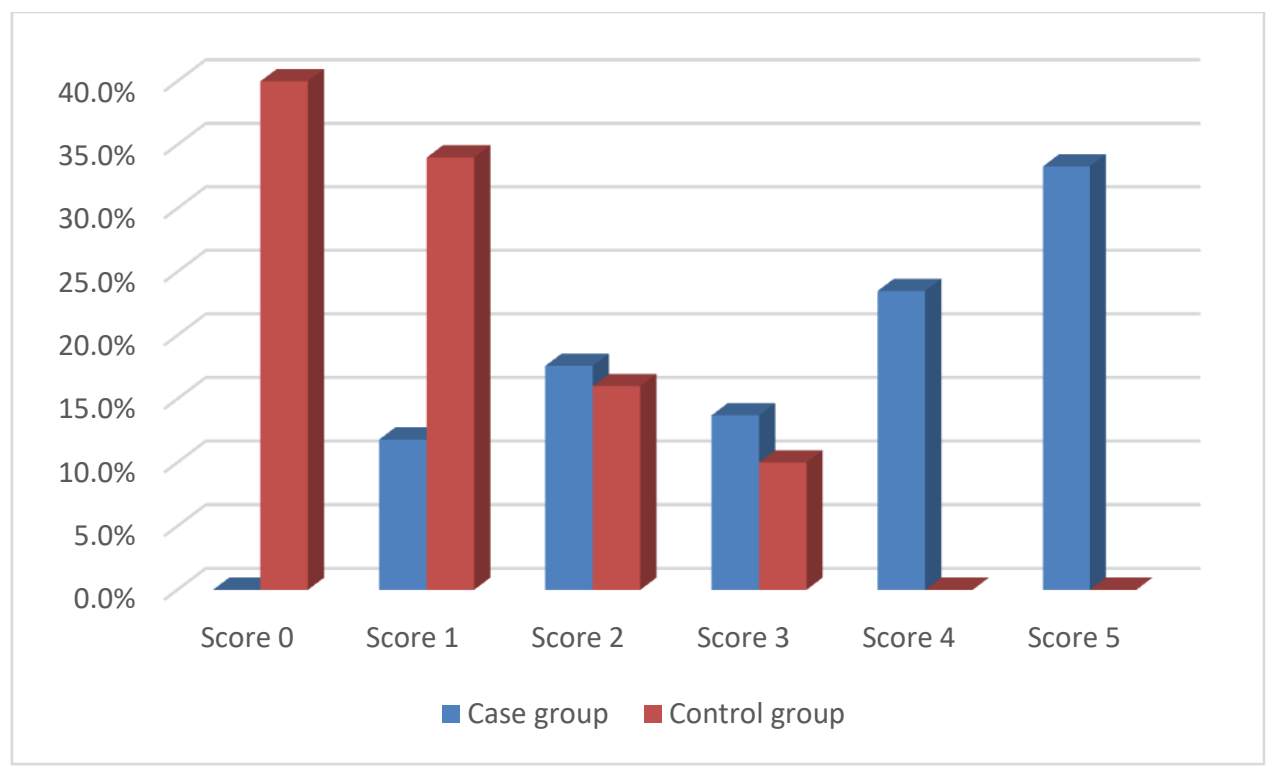

Figure (4): Multiple bar chart showing inter eye asymmetry among the studied groups.

\section{Discussion}

Keratoconus (KC) is a bilateral corneal, noninflammatory condition characterized by gradual thinning and apical protrusion. ${ }^{[20]}$ causing rapid decrease in the visual acuity early in the adulthood life. Several studies evaluated the demographic, clinical characteristics of patients with $\mathrm{KC}$ in different countries. ${ }^{[3,21,22]}$ The Pentacam topography is a reliable method to screen and diagnose cases with KC allowing early and effective management. $^{[23]}$ in Egypt topographic screening and refractive surgeries are becoming more popular among patients with refractive errors and that was helpful in our study. Pentacam HR tomographer

(OCULUS Optikgeräte GmbH, Germany) was the testing device in our study. The resolution of its images is five times that of the Pentacam ${ }^{\circledR}$ models as mentioned by OCULUS. ${ }^{[24]}$ Ozkan et al. ${ }^{[25]}$ and Rafati et al. ${ }^{[26]}$ also used the same device. Elbedewy et al.).

Saini et al. [27] obtained topographical records from a placido based system (Nidek ARK 10000, Japan) for demonstrating features of KC., Naderan et al. ${ }^{[28]}$ also obtained topographic measurments by OPDScan II (NidekCo. Ltd., Gamagori, Japan). The OPD-Scan uses Placido-based corneal topography to measure corneal aberrations. a malasian study ${ }^{[29]}$ used Orbscan II corneal topography system (Bausch and Lomb 
Surgical, Orbtek Inc., Salt Lake City, UT, USA). Reddy JC et al. ${ }^{[30]}$ obtained topography by using the Galilei dual Scheimpflug analyzer.

Our sample size was 101 patient; 51 patients with $\mathrm{KC}$ and 50 patients as a control group. Elbedewy et al. ${ }^{[23]}$ included 8124 subjects evaluated in his study, 91 subjects had KC in one or both eyes. Unilateral $\mathrm{KC}$ in only 5 cases.while 86 cases had bilateral KC. A total number of 177 eyes suffered from KC out of the 16,248 studied eyes. Rafati et al. ${ }^{[26]}$ evaluated the records of 1080 eyes of $540 \mathrm{KC}$ patients.

Ozkan et al. ${ }^{[25]}$ evaluated data of 3128 patients, Saini et al. ${ }^{[27]}$ studied 31 patients with 61 keratoconic eyes, Naderan et al. ${ }^{[28]}$ evaluated 320 patients in his study, 110 had $\mathrm{KC}, 60$ were FFKC, and 150 were normal. Castro-Luna et al. ${ }^{[31]}$ included 205 patients; 82 normal,40 early subclinical KC and 83 KC. A total of 234 patients with $\mathrm{KC}$ were included in the study by Alqudah et al. ${ }^{[20]}$ This study was designed as a retrospective cohort clinical study on KC patients. Many studies used the same design as Elbedewy et al. ${ }^{[23]}$, Rafati et al. ${ }^{[26]}$ Castro-Luna et al. ${ }^{[31]}$, Reddy et al. ${ }^{[30]}$, Ozkan et al. ${ }^{[25]}$ and Alqudah et al. ${ }^{[20]}$ however, Saini et al. ${ }^{[27]}$, Naderan et al. ${ }^{[28]}$ were prospective studies.
KC usually starts to develop at the age of puberty. In this study, the mean age of patients with $\mathrm{KC}$ at time of diagnosis was $29.25 \pm 8.13$ years old, which is very close to another study done in Egypt by Elbedewy et al. ${ }^{[23]}$ in which the mean age of onset was $29.40 \pm 9.79$ years old, Cruz-Becerril et al. ${ }^{[32]}$ with an onset at $28.14 \pm 10.30$ years of age, in European countries as the mean age of the $\mathrm{KC}$ patients at time of diagnosis was $23-28$ years ${ }^{[4,33,34]}$ and Ljubic study in which the mean age of onset was $26.81 \pm 1.25$ years $^{[35]}$. Meanwhile, the asian countries shows a younger age of onset; in a study by Assiri et al. in Saudi Arabia the mean age at diagnosis was slightly lower than in our study, about $18.5 \pm 3.9$ years ${ }^{[21]}$ and Saini et al. with mean age at time of diagnosis $20.2 \pm 6.4$ years. ${ }^{[27]}$

Concerning gender distribution, there was a predominance of the female gender with (66.7\%) of the $\mathrm{KC}$ cases and (33.3\%) for the male gender with no significant difference between them, This was in agreement with Elbedewy et al. ${ }^{[23]}$ in which females consist (54.9\%) and males (45.1\%).females also more in Ljubic study (52.9\%). ${ }^{[35]}$ However there are other studies with male predominance ${ }^{[29,36]}$. As in study by Rafati et al. ${ }^{[26]}$ in which males were $(70 \%)$.

When we analyzed the refractive parameters in this study, statistically significant 
differences were found between the $\mathrm{KC}$ and control groups regarding the cylinder, $\mathrm{p}$ value $<0.001$. but not for the sphere $(p$ $=0.988)$.

Reddy et al. ${ }^{[30]}$ also observed statistically significant differences for the cylinder $(\mathrm{p}<$ 0.001) not for the sphere $(\mathrm{p}=0.08)$, a study by Castro-Luna et al. ${ }^{[31]}$ found statistically significant differences for the sphere, the cylinder and the spherical equivalent $(\mathrm{p}<$ 0.05 ) as also found in a study by $\mathrm{Xu}$ et al. [37]

Saad and Gatinel ${ }^{[38]}$ obtained that the mean of the sphere was significantly higher in their normal group than in their early subclinical KC group $(\mathrm{p}<0.001)$.

However, Naderan et al. ${ }^{[28]}$ didn't find statistically significant differences for sphere $(\mathrm{p}=0.136)$ or cylinder $(\mathrm{p}=0.108)$

Regarding BCVA This study also found a significant negative correlation between severity of KC and BCVA. p value $(<0.001)$ many studies found the same result as the Saudi Arabian ${ }^{[21]}$, the malasian ${ }^{[29]}$ and the Egyptian ${ }^{[23]}$ studies.

We found no significant association between the severity of KC with age and sex. Similar finding was found in many studies ${ }^{[26,29,39] .}$ Other studies found the same regarding sex ${ }^{[36,40]}$ but not the age; some studies found that $\mathrm{KC}$ is more in younger age groups ${ }^{[36,41]}$.
A study in jordan ${ }^{[20]}$ found no correlation between severity and age but regarding sex; the study found that females were more likely to have severe $\mathrm{KC}$ than males attributing this to the effect of hormonal levels in the biomechanics of cornea and so the progression of $\mathrm{KC}$. $^{[42,43]}$

Regarding severity; our study found that $\mathrm{KC} 1$ consist of $(27.4 \%)$ of cases and $\mathrm{KC} 2$ were $(29.4 \%)$ while $\mathrm{KC} 3(11.7 \%)$ and $\mathrm{KC} 4$ $(9.8 \%)$ so most of our cases were mild to moderate which is consistent with many studies as that done in malasia ${ }^{[29]}$ found that $37.6 \%$ were stage I, $30.1 \%$ stage II, $4.4 \%$ stage III and $27.8 \%$ stage IV at the time of diagnosis. in Saudi Arabia it was found that $39.2 \%$ were in the early stage, $42.5 \%$ in the moderate stage and $18.3 \%$ in the advanced one ${ }^{[21]}$. A study by shanti et al. ${ }^{[4]}$ found that $62 \%$ had mild form, $28.1 \%$ had moderate $\mathrm{KC}$ and $9.9 \%$ had severe $\mathrm{KC}$. Elbedewy et al. ${ }^{[23]}$ found that $54.2 \%$ of the affected eyes had a mild degree of $\mathrm{KC}, 27.1 \%$ had a moderate degree, while $18.7 \%$ suffered from the severe form. also a study in Jordan [20] found that most of the eyes were mild $63.3 \%$, followed by moderate $24.7 \%$, and then severe $11.9 \%$. however a study in Iran [26] found that The frequency of moderate $(56.4 \%)$ and severe $(28.4 \%) \mathrm{KC}$ was more than mild cases (15.2\%) and said this 
because patients with more severe disease seek medical advice more.

We found that the anterior and posterior curvature indices were significantly higher in $\mathrm{KC}$ group than control group which is the same finding by Piñero et al. $^{[9]}$ and Tomidokoro et al. ${ }^{[45]}$ regarding pachymetry we found that the central thickness significantly lower in $\mathrm{KC}$ group than control group and also significantly decrease with increase grading of $\mathrm{KC}$ therefore, corneal thinning in eyes with $\mathrm{KC}$ can be accurately monitored using the Scheimpflug imaging system. these findings are consistent with Piñero et al. ${ }^{[9]}$ and Emre et al. ${ }^{[46]}$

Regarding corneal asphericity, Q value of eyes with $\mathrm{KC}$ had a more significant prolate shape (negative asphericity) than normal eyes, Several studies evaluated the correlation of anterior curvature and asphericity and reported controversial results; our findings agreed with that by Piñero et al. ${ }^{[9]}$, one rejected such correlation $^{[47]}$ and another has reported a poor correlation. ${ }^{[48]}$ However we found Q value in early $\mathrm{KC}$ cases normal in $100 \%$ of FFKC and in $80 \%$ of $\mathrm{KC} 1$.

Regarding thickness profile map average (PPI average), keratometry and elevation values for anterior and posterior surface, they were significantly higher in $\mathrm{KC}$ group than in control group. a study by Müftüoğlu et al. $^{[49]}$ found nearly the same results regarding PPI, keratometry, and posterior elevation values while comparing eyes with clinical, subclinical $\mathrm{KC}$ and normal eyes.

Ambrosio et al. [50] emphasized the importance of the relative corneal thickness indices instead of relying on point measurements. They introduced new indices named Maximum Ambrosio Relational Thickness "ARTmax". We found that it is highly significant in differentiating between control group and $\mathrm{KC}$ group.

Our findings showed that BAD_D was very important in the diagnosis of $\mathrm{KC}$ which is in agreement with other studies ${ }^{[51,52,53]}$.

We found BAD_D and ARTmax values are normal in $100 \%$ of control group and abnormal in $100 \%$ of $\mathrm{KC} 2,3,4$ but in early KC BAD_D values were more abnormal than ARTmax. Which is evident by other studies ${ }^{[51,52]}$.

Regarding Aberrometric indices we found that RMS total, RMS HOA, 3rd Ver. coma total, 3rd Hor. coma total, 5th Ver. coma total, 5th Hor. coma total were highly significant between control and $\mathrm{KC}$ group. Ozkan et al. ${ }^{[25]}$ found the same except for 3rd Hor. coma total and 5th Hor. coma total; their difference was insignificant. 
There is an increased inter-eye asymmetry in keratoconic patients compared to subjects with normal corneas and this is also evident by studies. ${ }^{[54]}$

\section{Conclusion:}

We found no significant difference between groups regarding age or gender. Many parameters in topography and tomography were efficient in differentiating normal cases from keratoconus cases even in early disease. Q value was normal in most early $\mathrm{KC}$ cases so it is not advisable to use this parameter alone in differentiating normal and $\mathrm{KC}$ cases. Inter-eye asymmetry score in keratoconic patients increased compared to subjects with normal corneas.

\section{References:}

1. Rabinowitz YS. Keratoconus. Surv Ophthalmol, 1998; 42(4): 297-319.

2. Davidson AE, Hayes S, Hardcastle AJ, Tuft SJ. The pathogenesis of eratoconus. Eye (Lond) 2014; 28 (2): 189-95.

3. Rafati S, Hashemi H, Nabovati P, Doostdar A, Yekta A, Aghamirsalim M, et al. Demographic profile, clinical, and topographic characteristics of keratoconus patients attending at a tertiary eye center. Journal of current ophthalmology. 2019; 31(3):268-74.
4. Georgiou T, Funnell CL, Cassels-Brown A, O'conor R. Influence of ethnic origin on the incidence of keratoconus and associated atopic disease in Asians and white patients. Eye. 2004; 18(4):379-83.

5. Gokhale NS. Epidemiology of keratoconus. Indian J Ophthalmol, 2013; 61(8): 382-3.

6. Gordon-Shaag A, Millodot M, Shneor E, Liu Y. The genetic and environmental factors for keratoconus. Biomed Res Int, 2015. 2015: p. 795738 .

7. Krachmer JH, Feder RS, Belin MW. Keratoconus and related noninflammatory corneal thinning disorders. Surv Ophthalmol, 1984; 28(4): 293-322.

8. Mannion LS, Tromans C, O'Donnell C. Reduction in corneal volume with severity of keratoconus. Current eye research. 2011; 36(6):522-7.

9. Piñero DP, Alió JL, Alesón A, Vergara ME, Miranda M. Corneal volume, pachymetry, and correlation of anterior and posterior corneal shape in subclinical and different stages of clinical keratoconus. Journal of Cataract \& Refractive Surgery. 2010; 36(5):814-25.

10. Gomes JA, Tan D, Rapuano CJ, Belin MW, Ambrósio R, Jr., et al. Global consensus on keratoconus and ectatic diseases. Cornea. 2015; 34(4):359-69.

11. Tur VM, MacGregor C, Jayaswal R, O'Brart D, Maycock N. A review of keratoconus: diagnosis, pathophysiology, and genetics. Survey of ophthalmology. 2017; 62(6):770-83. 
12. Kovács $\mathbf{I}$, Miháltz $\mathrm{K}$, Kránitz $\mathrm{K}$, Juhász É, Takács Á, Dienes L, et al. Accuracy of machine learning classifiers using bilateral data from a Scheimpflug camera for identifying eyes with preclinical signs of keratoconus. Journal of Cataract \& Refractive Surgery. 2016; 42(2):27583.

13. Gokul A, Vellara HR, Patel DV. Advanced anterior segment imaging in keratoconus: a review. Clinical \& experimental ophthalmology. 2018; 46(2):122-32.

14. Belin MW, Khachikian SS. An introduction to understanding elevation-based topography: how elevation data are displayed-a review. Clinical \& experimental ophthalmology. 2009; 37(1):14-29.

15. Fan R, Chan TC, Prakash G, Jhanji V. Applications of corneal topography and tomography: a review. Clinical \& experimental ophthalmology. 2018; 46(2):133-46.

16. Amsler M. [The "forme fruste" of keratoconus]. Wien Klin Wochenschr, 1961; 73: 842-3.

17. Wagner H, Barr JT, Zadnik K, Collaborative Longitudinal Evaluation of Keratoconus (CLEK) Study Group. Collaborative Longitudinal Evaluation of Keratoconus (CLEK) Study: methods and findings to date. Contact Lens and Anterior Eye. 2007; 30(4):223-32.

18. Belin MW, Duncan JK. Keratoconus: the ABCD grading system. Klinische Monatsblätter für Augenheilkunde. 2016; 233(06):701-7.

19. McAlinden C, Khadka J, Pesudovs K. A comprehensive evaluation of the precision (repeatability and reproducibility) of the Oculus Pentacam HR. Investigative ophthalmology \& visual science. 2011; 52(10):7731-7.
20. Alqudah N, Jammal H, Khader Y, Al-Dolat W, Alshamarti S, Shannak Z. Characteristics of Keratoconus Patients in Jordan: HospitalBased Population. Clinical Ophthalmology (Auckland, NZ). 2021;15:881.

\section{Assiri AA, Yousuf BI, Quantock AJ, Murphy}

PJ. Incidence and severity of keratoconus in Asir province, Saudi Arabia. British Journal of Ophthalmology. 2005; 89(11):1403-6.

22. Millodot M, Shneor E, Albou S, Atlani E, Gordon-Shaag A. Prevalence and associated factors of keratoconus in Jerusalem: a crosssectional study. Ophthalmic epidemiology. 2011; 18(2):91-7.

23. Elbedewy HA, Wasfy TE, Soliman SS, Sabry MM, Awara AM, El Emam SY, et al. Prevalence and topographical characteristics of keratoconus in patients with refractive errors in the Egyptian delta. International ophthalmology. 2019; 39(7):1459-65

24. https://www.oculus.de/us/products/anteriorsegment-analysis/pentacam-pentacam-hrpentacam-axl/

25. Ozkan HH, Koc M, Kiziltoprak H, Tekin K, Aydemir E. Evaluation of topographic, tomographic, topometric, densitometric, and aberrometric features of cornea with pentacam HR system in subclinical keratoconus. International Ophthalmology. 2021; 41(5):172941.

26. Rafati S, Hashemi H, Nabovati P, Doostdar A, Yekta A, Aghamirsalim M, et al. Demographic profile, clinical, and topographic characteristics of keratoconus patients attending at a tertiary eye center. Journal of current ophthalmology. 2019; 31(3):268-74. 
27. Saini JS, Saroha V, Singh P, Sukhija JS, Jain AK. Keratoconus in Asian eyes at a tertiary eye care facility. Clinical and Experimental Optometry. 2004; 87(2):97-101.

28. Naderan M, Jahanrad A, Farjadnia M. Ocular, corneal, and internal aberrations in eyes with keratoconus, forme fruste keratoconus, and healthy eyes. International ophthalmology. 2018; 38(4):1565-73.

29. Mohd-Ali B, Abdu M, Yaw CY, Mohidin N. Clinical characteristics of keratoconus patients in Malaysia: a review from a cornea specialist centre. Journal of Optometry. 2012; 5(1):38-42.

30. Reddy JC, Rapuano CJ, Cater JR, Suri K, Nagra PK, Hammersmith KM. Comparative evaluation of dual Scheimpflug imaging parameters in keratoconus, early keratoconus, and normal eyes. Journal of Cataract \& Refractive Surgery. 2014; 40(4):582-92.

31. Castro-Luna G, Pérez-Rueda A. A predictive model for early diagnosis of keratoconus. BMC ophthalmology. 2020; 20(1):1-9.

32. Cruz-Becerril A, Valdivia A, Peralta $R$, Domínguez-Fernández RN, Castro-Reyes MA. Prevalence of refractive errors in Mexican patients with keratoconus. Clinical Optometry. 2015; 7:39-44.

33. Nielsen K, Hjortdal J, Ehlers N. Incidence and prevalence of keratoconus in Denmark. Acta ophthalmologica Scandinavica. 2007; 85(8):8902.

34. Barrientos YF, Moreno SG, Soto ML. Estimated prevalence and clinical characteristics of keratoconus in the healthcare setting of the Hospital Costa del Sol, Spain. Journal of Emmetropia: Journal of Cataract, Refractive and Corneal Surgery. 2014;5(1):15-21.
35. Ljubic AD. Keratoconus and its prevalence in Macedonia. Macedonian Journal of Medical Sciences. 2009; 2(1).

36. Ertan A, Muftuoglu O. Keratoconus clinical findings according to different age and gender groups. Cornea. 2008; 27(10):1109-13.

37. Xu Z, Li W, Jiang J, Zhuang X, Chen W, Peng M, et al. Characteristic of entire corneal topography and tomography for the detection of sub-clinical keratoconus with Zernike polynomials using Pentacam. Scientific reports. 2017; 7(1): 16486.

38. Saad A, Gatinel D. Evaluation of total and corneal wavefront high order aberrations for the detection of forme fruste keratoconus. Investigative ophthalmology \& visual science. 2012; 53(6):2978-92.

39. Abdu M, Binnawi KH, Hassan R. Clinical profile of keratoconus patients in Sudan. Sudanese Journal of Ophthalmology. 2016; 8(1):20-25.

40. Fink BA, Sinnott LT, Wagner H, Friedman C, Zadnik K, CLEK Study Group. The influence of gender and hormone status on the severity and progression of keratoconus. Cornea. 2010; 29(1):65-72.

41. Rashid ZA, Millodot M, Evans KS. Characteristics of keratoconic patients attending a specialist contact lens clinic in Kenya. Middle East African journal of ophthalmology. 2016; 23(4):283.

42. McKay TB, Hjortdal J, Sejersen H, Asara JM, Wu J, Karamichos D. Endocrine and metabolic pathways linked to keratoconus: implications for the role of hormones in the stromal microenvironment. Scientific reports. 2016; 6(1):1-2. 
43. Spoerl E, Zubaty V, Raiskup-Wolf F, Pillunat LE. Oestrogen-induced changes in biomechanics in the cornea as a possible reason for keratectasia. British Journal of Ophthalmology. 2007; 91(11):1547-50.

44. Shanti Y, Beshtawi I, Zyoud SeH, Abu-Samra A, Abu-Qamar A, Barakat R, et al. Characteristics of keratoconic patients at two main eye centres in Palestine: a cross-sectional study. BMC ophthalmology. 2018;18(1):95.

45. Meek KM and Boote $C$. The organization of collagen in the corneal stroma. Exp Eye Res, 2004; 78(3): 503-12.

46. Emre S, Doganay S, Yologlu S. Evaluation of anterior segment parameters in keratoconic eyes measured with the Pentacam system. Journal of Cataract \& Refractive Surgery. 2007; 33(10):1708-12.

47. Davis WR, Raasch TW, Mitchell GL, Mutti DO, Zadnik K. Corneal asphericity and apical curvature in children: a cross-sectional and longitudinal evaluation. Investigative ophthalmology \& visual science. 2005; 46(6):1899-906.

48. Zhang Z, Wang J, Niu W, Ma M, Jiang $K$, Zhu P, et al. Corneal asphericity and its related factors in 1052 Chinese subjects. Optometry and Vision Science. 2011; 88(10):1232-9.
49. Muftuoglu O, Ayar O, Ozulken K, Ozyol E, Akıncı A. Posterior corneal elevation and back difference corneal elevation in diagnosing forme fruste keratoconus in the fellow eyes of unilateral keratoconus patients. Journal of Cataract \& Refractive Surgery. 2013; 39(9):1348-57.

50. Ambrósio R, Jr., Caiado AL, Guerra FP, Louzada R, Sinha RA, et al. Novel pachymetric parameters based on corneal tomography for diagnosing keratoconus. Journal of refractive surgery (Thorofare, NJ : 1995). 2011;27(10):753-8.

51. Ambrósio R, Faria-Correia F, Ramos I, Valbon BF, Lopes B, Jardim D, et al. Enhanced screening for ectasia susceptibility among refractive candidates: the role of corneal tomography and biomechanics. Current Ophthalmology Reports. 2013; 1(1):28-38.

52. Hashemi H, Beiranvand A, Yekta A, Maleki A, Yazdani N, Khabazkhoob M. Pentacam top indices for diagnosing subclinical and definite keratoconus. Journal of current ophthalmology. 2016; 28(1):21-6.

53. Correia FF, Ramos I, Lopes B, Salomao MQ, Luz A, Correa RO, et al. Topometric and tomographic indices for the diagnosis of keratoconus. Int J Kerat Ect Cor Dis. 2012; 1(2):92-9.

54. Dienes L, Kránitz K, Juhász E, Gyenes A, Takács A, Miháltz K, et al. Evaluation of intereye corneal asymmetry in patients with keratoconus. A Scheimpflug imaging study. PloS one. 2014; 9(10):e108882.

To cite this article: Esraa A. AbdElkader, Abdelmonem M. Hamed, Ahmed A. Tabl. Refractive , Topographic and Tomographic analysis of Keratoconus in Egypt. BMFJ 2022;39 (ophthalmology):71-89. DOI: 10.21608/bmfj.2021.86232.1445 